\title{
Giant pleomorphic adenoma of the parotid gland extending to the parapharyngeal space: A rare case report
}

\author{
Abdulwahid M. Salih, Fahmi H. Kakamad, Shakhawan M. Ali, \\ Imad J. Habibullah, Payman Kh. Mahmud
}

\begin{abstract}
Introduction: Parotid gland tumor with extension to the parapharyngeal space is a rare condition. The aim of this study is to report an extremely rare condition of deep lobe parotid gland tumor involving the parapharyngeal space. Case Report: A 49-year-old female presented with a large growth on the left side of the face, which enlarged gradually over a period of 10 years. Radiological investigations determined the exact location and extent of the tumor. Complete resection was performed with a favorable outcome. Conclusion: Pleomorphic adenoma with parapharyngeal extension is a rare but difficult to be managed benign tumor of the salivary glands. However, in selected cases, the submandibular transcervical approach without an osteotomy can be safe.
\end{abstract}

Abdulwahid M. Salih', Fahmi H. Kakamad²,3, Shakhawan M. Ali $^{4}$, Imad J. Habibullah ${ }^{3}$, Payman Kh. Mahmud ${ }^{5}$

Affiliations: ${ }^{1}$ Faculty of Medical Sciences, School of Medicine, Department Surgery, University of Sulaimani, François Mitterrand Street, Sulaimani, Kurdistan, Iraq; ${ }^{2}$ Faculty of Medical Sciences, School of Medicine/Department Cardiothoracic and Vascular Surgery, University of Sulaimani, François Mitterrand Street, Sulaimani, Kurdistan, Iraq; ${ }^{3}$ Kscien Organization for Scientific Research, Hamdi Street, Azadi Building, Sulaimani, Kurdistan, Iraq; ${ }^{4}$ Sulaimany Teaching Hospital, Department of Maxillofacial Surgery, Sulaimani, Kurdistan Region, Iraq; ${ }^{5}$ Sulaimany Teaching Hospital, Oral medicine Department, Sulaimani, Kurdistan Region, Iraq.

Corresponding Author: Fahmi H. Kakamad, Faculty of Medical Sciences, School of Medicine/Department Cardiothoracic and Vascular Surgery, University of Sulaimani, François Mitterrand Street, Sulaimani, Kurdistan, Iraq. Email: fahmi. hussein@univsul.edu.iq

Received: 01 March 2018

Accepted: 18 April 2018

Published: 23 May 2018
Keywords: Parapharyngeal space, Parotid tumor, Pleomorphic adenoma, Submandibular

\section{How to cite this article}

Salih AM, Kakamad FH, Ali SM, Habibullah IJ, Mahmud PK. Giant pleomorphic adenoma of the parotid gland extending to the parapharyngeal space: A rare case report. Int $\mathrm{J}$ Case Rep Images 2018;9:100914Z01AS2018.

Article ID: 100914Zo1AS2018

$* * * * * * * * *$

doi: 10.5348/100914Z01AS2018CR

\section{INTRODUCTION}

Pleomorphic adenoma, which is a benign salivary gland mixed tumor, constitutes up to two-thirds of all neoplasms of the salivary gland [1]. It is located in the parotid glands in $85 \%$ of the cases, the remainders affect the submandibular glands (5\%) and minor salivary glands (10\%) [2].The two differentiating characteristics of Pleomorphic adenoma are frequent malignant conversion and high recurrence rate. Asymptomatic swelling is the most common mode of presentation. Increase in growth rate, changes in consistency, invasion of facial nerve are among the alarming signs of malignant conversion [3, 4].

In the majority of the cases, superficial lobe of the parotid gland hosts the pathology. However, in rare cases the deep lobe will be affected as well, extension into the parapharyngeal space is even rarer with limited experience in presentation, clinical courses, diagnosis and management [5]. Due to its anatomical location, management of any disease in the parapharyngeal space is a challenging issue to the physician [6]. The area is an 


\section{EDORIUM Journals}

inverted pyramid, the base of which is formed by the base of the cranium (small portion of petrosal bone), and the apex defines the joint between the posterior belly of the digastric muscle and the greater cornu of the hyoid bone. [6].

The aim of this study is to report a case of large pleomorphic adenoma of parotid gland in a female patient involving deep lobe extending into the parapharyngeal space with focus on the diagnosis and the surgical approach.

\section{CASE REPORT}

A 49-year-old female patient was referred to department of general surgery with a chief complaint of swelling in the left side of the jaw for ten years which increased in size gradually over the last eight months. She denied any odynophagia, respiratory distress, dysphagia, otalgia or weight loss. There was a non-mobile, not tender, 5x4 cm swelling in the left mandibular angle and submandibular region with solid consistency. On nasal endoscopy, submucosal fullness was seen in the left nasopharynx; on laryngoscopy, the left oropharyngeal fullness was seen extending to the hypopharynx. However, the true vocal folds were mobile bilaterally, and the airway remained patent. Magnetic resonance imaging (MRI) of the neck demonstrated a left-sided 7x4X5 cm parapharyngeal mass, causing muscle displacement without fat plane between the deep lobe and the mass. Radiographically, these features were consistent with the neoplasm of the deep-lobe (Figures 1). Extra oral fine needle aspiration cytology (FNAC) was performed under ultrasound guide which showed admixed epithelial, myoepithelial and mesenchymal components consistent with pleomorphic adenoma (Figure 2). The patient underwent excision of the mass via a trans-parotid and trans cervical approach. The facial nerve and its branches were preserved and the tumor was excited in toto without mandibular osteotomy. The patient tolerated the procedure well, and she recovered uneventfully. Findings on histologic evaluation were consistent with a pleomorphic adenoma. The patient was free of symptoms two months after operation.

\section{DISCUSSION}

Parapharyngeal space neoplasm arising from the salivary gland is an exceptional condition which occurs in the fourth and sixth decades of life $[7,8]$. The current case reported in a 49 year-old patient. It presents with a high rate of recurrence even if it resembles a benign neoplasm due to the few symptoms complained of by the patient and extension into the hidden site (parapharyngeal space) [9]. They are generally discovered, during routine physical examination, as an asymptomatic mass. They may appear as a cervical swelling, as in the current case,

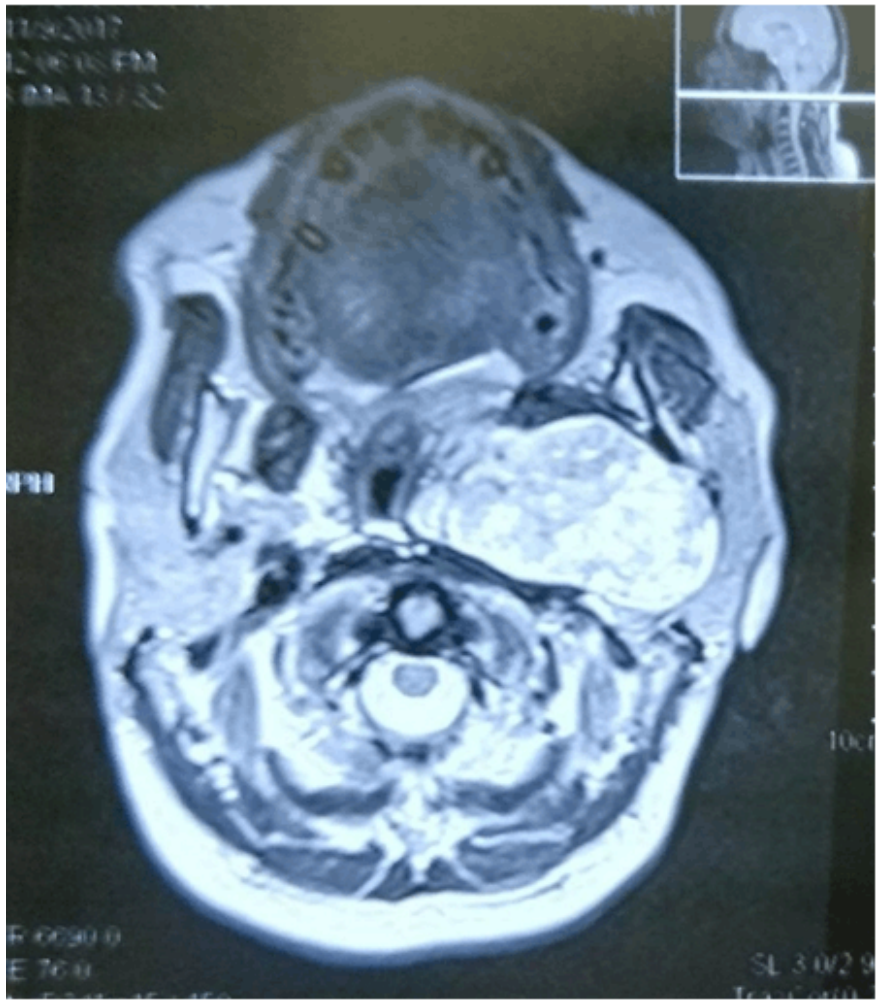

Figure 1: Axial and sagittal MRI scan showing extension of swelling from deep lobe of parotid gland into the left parapharyngeal space invading oropharynx.

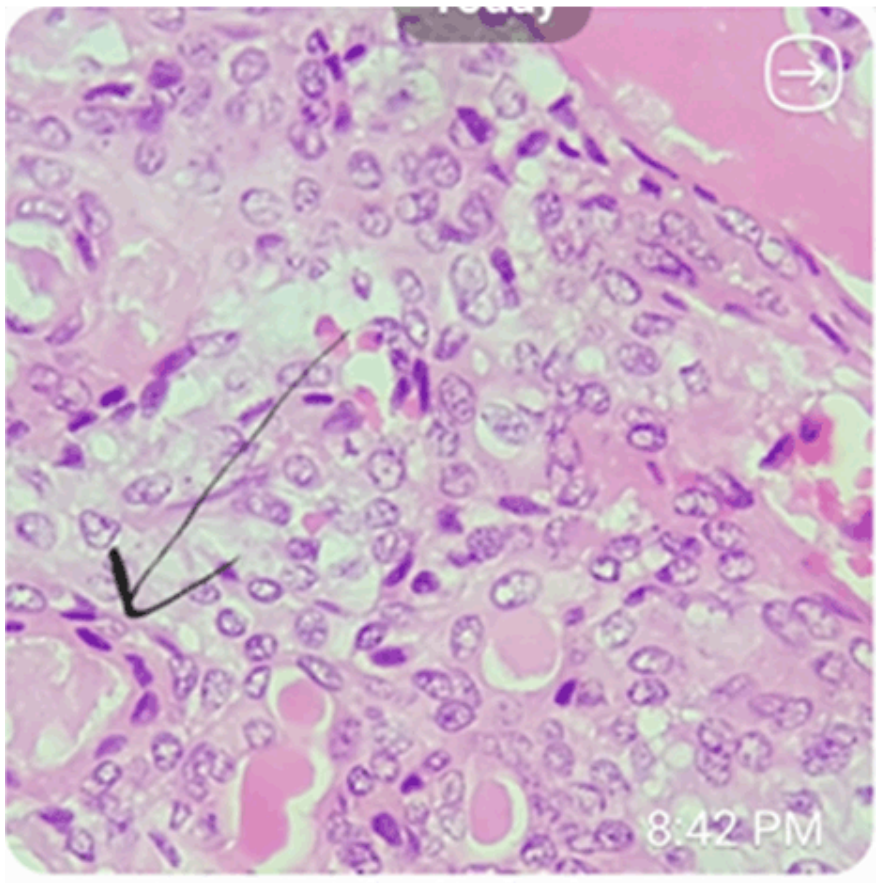

Figure 2: Excisional biopsy shows paranchymatous gland with myoepithelium, stroma with epithelial tissue (the arrow).

or as an intra-oral mass. They remain silent for a long period of time [10]. Diagnostic imaging, such as computed tomography (CT) or MRI, is mandatory: MRI is superior to other modality owing that it determines the margins 


\section{EDORIUM Journals}

and their relationship with the surrounding tissues [10]. MRI suggested the diagnosis in the current case.

Controversy exists regarding the use of FNAC in the diagnostic procedures due to localization of these lesions and their relationship with the vascular and nervous structures that can be damaged by this kind of examination [11]. In their study, Munir and his associates analyzed the 10 year registry which recorded 30 patients with deep lobe pleomorphic adenoma, in eighteen (72\%) cases, FNAC was performed and pleomorphic adenoma was confirmed in fourteen cases [12-14]. The present case was diagnosed pre-operatively by FNAC and confirmed by excisional biopsy.

The treatment of these tumors is the most challenging part to the head and neck surgeon because of the hidden location of the tumor with very critical nearby structures such as large vessels of the neck, sympathetic chain, lymph nodes, and lower cranial nerves [10]. Spitting of the mandible is a necessary step in most of the approaches [15]. However, in our case, division of the mandible was not practiced because of the prestyloid localization of tumor, which permitted total excision of the neoplasm without injury the surrounding vital structures.

\section{CONCLUSION}

Pleomorphic adenoma is a benign epithelial tumor arising from the salivary glands.Extension into the parapharyngeal space is a difficult to be managed variant. MRI and FNAC helps proper preoperative diagnosis and careful plane to surgical resection, in selected cases of parapharyngeal space benign tumours, the neoplasm can be resected with mandibular preservation.

\section{REFERENCES}

1. Califano J, Eisele DW. Benign salivary gland neoplasms. Otolaryngol Clin North Am 1999 Oct;32(5):861-73.

2. Luna MA. Salivary glands. In: Pilch BZ, editor. Head and Neck Surgical Pathology. Philadelphia: Lippincott Williams \& Wilkins; 2001: p. 284-349.

3. Carr RJ, Bowerman JE. A review of tumours of the deep lobe of the parotid salivary gland. $\mathrm{Br} \mathrm{J}$ Oral Maxillofac Surg 1986 Jun;24(3):155-68.

4. Guruprasad Y, Chauhan DS. Deep lobe parotid gland pleomorphic adenoma involving the parapharyngeal space. Med J DY Patil Univ 2012;5:62-5.

5. Morita N, Miyata K, Sakamoto T, Wada T. Pleomorphic adenoma in the parapharyngeal space: Report of three cases. J Oral Maxillofac Surg 1995 May;53(5):605-10.

6. Batsakis JG, Sneige N. Parapharyngeal and retropharyngeal space diseases. Ann Otol Rhinol Laryngol 1989 Apr;98(4 Pt 1):320-1.

7. Carrau RL, Myers EN, Johnson JT. Management of tumors arising in the parapharyngeal space. Laryngoscope 1990 Jun;100(6):583-9.
8. Hughes KV 3rd, Olsen KD, McCaffrey TV. Parapharyngeal space neoplasms. Head Neck 1995 Mar-Apr;17(2):124-30.

9. Ellis GL, Auclair PL. Tumour of the Salivary Glands, Atlas of Tumor Pathology. Washington, DC: Armed Forces Institute of Pathology; 1995. p. 39-41.

10. Izzo L, Frati R, Cianfrone F, et al. Parotid gland cancer: A case report of a primitive adenocarcinoma arising from a multirecurrent pleomorphic adenoma. J Exp Clin Cancer Res 2004 Mar;23(1):153-6.

11. Sergi B, Limongelli A, Scarano E, Fetoni AR, Paludetti G. Giant deep lobe parotid gland pleomorphic adenoma involving the parapharyngeal space. Report of three cases and review of the diagnostic and therapeutic approaches. Acta Otorhinolaryngol Ital 2008 Oct;28(5):261-5.

12. Munir N, Baldwin D, Mal R. Deep lobe parotid pleomorphic adenoma: Ten year retrospective review of cases treated at a United Kingdom regional tertiary referral center. Internet J Head Neck Surg 2006;1(1).

13. Ciecior E, Sowa P, Adamczyk-Sowa M, Wolny A, Mrowka-Kata K. Huge pleomorphic adenoma of deap lobe origin in the parotid gland. [Article in Polish]. Otolaryngol Pol 2009 Sep;63(7):87-8.

14. SalgarelliAC,CapparèP, Bellini P, Collini M. Usefulness of fine-needle aspiration in parotid diagnostics. Oral Maxillofac Surg 2009 Dec;13(4):185-90.

15. Bozza F, Vigili MG, Ruscito P, Marzetti A, Marzetti F. Surgical management of parapharyngeal space tumours: Results of 10-year follow-up. Acta Otorhinolaryngol Ital 2009 Feb;29(1):10-5.

$* * * * * * * * *$

\section{Author Contributions}

Abdulwahid M. Salih - Substantial contributions to conception and design, Analysis and interpretation of data, Revising it critically for important intellectual content, Final approval of the version to be published

Fahmi H. Kakamad - Substantial contributions to conception and design, Drafting the article, Revising it critically for important intellectual content, Final approval of the version to be published

Shakhawan M. Ali - Analysis and interpretation of data, Drafting the article, Final approval of the version to be published

Imad J. Habibullah - Acquisition of data, Revising it critically for important intellectual content, Final approval of the version to be published

Payman Kh. Mahmud - Analysis and interpretation of data, Drafting the article, Final approval of the version to be published

\section{Guarantor of Submission}

The corresponding author is the guarantor of submission.

\section{Source of Support}

None 


\section{EDORiUM Journals}

\section{Consent Statement}

Written informed consent was obtained from the patient for publication of this case report.

\section{Conflict of Interest}

Authors declare no conflict of interest.

\section{Copyright}

(C) 2018 Abdulwahid M. Salih et al. This article is distributed under the terms of Creative Commons Attribution License which permits unrestricted use, distribution and reproduction in any medium provided the original author(s) and original publisher are properly credited. Please see the copyright policy on the journal website for more information.
Access full text article on other devices

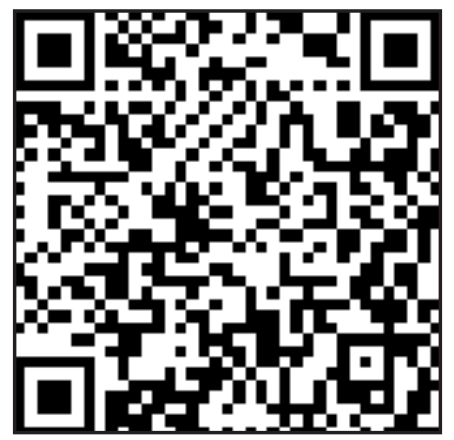

Access PDF of article on other devices

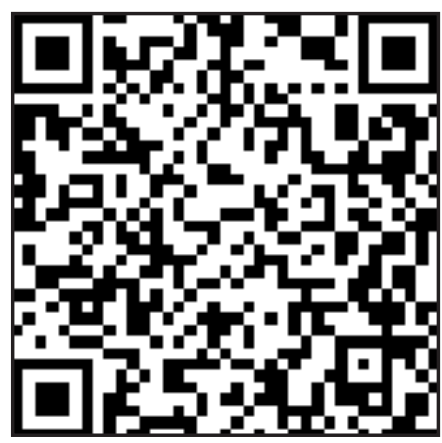

